\title{
Matrize polimerikodun konposite magnetikoen sorrera
}

\section{(Generation of magnetic composites with polymeric matrix)}

\author{
Eneko Ander Aketxe-Bilbao ${ }^{1}$, Leire Ruiz-Rubio ${ }^{1,2}$, Antonio Veloso-Fernández*1 \\ ${ }^{1}$ Kimika Fisikoa Saila, Zientzia eta Teknologia Fakultatea FCT/ZTF, \\ Euskal Herriko Unibertsitatea (UPV/EHU) \\ ${ }^{2}$ BCMaterials, Basque Centre for Materials, Applications and Nanostructures
}

\begin{abstract}
LABURPENA: Konpositeak propietate desberdinak dituzten bi konposatuz (edo gehiagoz) osatutako materialak dira, gaur egun oso erabiliak. Normalean, konposatu ugarienari matrizea deritzo, eta han barreiatzen den konposatuari gehigarria edo karga deitzen zaio. Material hauen erabilpena hainbat esparrutara zabaltzen da, esaterako eraikuntzetako hormigoi armatuetara eta surf oholen beiradun plastikoetara. Hau da, ia toki guztietan aurkitu daitezke material konposatuak, eta gaur egungo teknologia-garapenaren ikerketa-arloan ere ez dira salbuespen. Ikerketa hauetan gehienbat matrize polimerikodun konpositeetan ikertu dira, matrize polimerikoak eskaintzen dituen propietateak oso aplikazio tarte zabala dakarrelako. Matrize polimerikodun hauen artean poliuretanoen erabilpena gero eta gehiago sustatzen ari da, dituen propietate elastikoengatik eta sortzeko errazak direlako, naturan inpaktu handirik izan barik. Horrekin batera, gaur egungo poliuretanoen garapena asko handitu da, dituzten aldakortasun eta aplikazio ugariei esker. Bestalde, estimulu magnetikoei erantzuna emateko eta material adimenduak garatzeko partikula magnetikoak konpositeetan barreiatzea oso interesgarria da. Partikula magnetikoen propietateak, egitura, tamaina eta sortuak izateko jasan duten tratamenduek determinatzen dituzte, eta, horren arabera, izaera ezberdinekoak izan daitezke: paramagnetikoak, ferromagnetikoak, ferrimagnetikoak, diamagnetikoak edo antiferromagnetikoak. Lan honetan, film itxurako konpositeak sortu eta aztertu dira, eta poliuretanozko matrizean kobaltozko ferritak $\left(\mathrm{CoFe}_{2} \mathrm{O}_{4}\right)$, partikula ferromagnetikoak barreiatu dira. Materialak karakterizatzeko trakzio proba. Ekorketazko Kalorimetria Diferentziala (DSC) eta Lagin Bibrazionaleko Magnetometria (VSM) teknikak erabili dira. Lortutako konpositeek, eremu magnetiko estimuluaren eraginez, bere gainazala eraldatzeko aukera izango dute. Beraz, konposite hauen erabilpena zabaldu daiteke energia garbiaren erauzketarako, mikrotxipetarako, ordenagailuetarako edo urpekaritza jantzietarako.
\end{abstract}

HITZ-GAKOAK: poliuretanoa, partikula magnetikoak, konpositeak, material ferromagnetikoak, histeresi kurbak.

ABSTRACT: Composites are materials that are currently widely used and have two (or more) materials with different properties. Namely, they consist of a matrix and a dispersed material, an additive or filler. The use of these materials can be found from reinforced concrete in buildings to plastic glazing of surfboards. This means that composite materials can be found almost everywhere, and they are no exception in the field of current technology development research. In these studies it has been mostly investigated in polymeric matrix composites because the properties offered by the polymeric matrix lead to a very wide range of applications. Among these polymeric matrixes, the use of polyurethanes is increasingly being promoted due to their elastic properties and their ease of creation, without much impact on nature. Along with this, the development of current polyurethanes has greatly increased, thanks to their many variability and applications. On the other hand, it is very interesting to scatter magnetic particles in composites in response to magnetic stimuli and to develop intelligent materials. The properties of the magnetic particles are determined by the form, size and by the treatments they have undergone in order to be formed and according to this they can be of different nature: paramagnetic, ferromagnetic, ferromagnetic, diamagnetic or antiferromagnetic. In this work, film appearance composites have been created and analysed, in which the cobalt ferrites $\left(\mathrm{CoFe}_{2} \mathrm{O}_{4}\right)$ ferromagnetic particles have been dispersed in the polyurethane matrix. Tensile testing, Differential Scanning Calorimetry (DSC) and Vibrational Sample Magnetometry (VSM) techniques were used to characterize the materials. The composites obtained will be able to transform their surface under the influence of a magnetic field stimulus. Therefore, the use of these composites can be extended to clean energy extraction, microchips, computer or diving suits.

KEYWORDS: polyurethane, magnetic particles, composites, ferromagnetic materials, hysteresis curve.

* Harremanetan jartzeko / Corresponding author: Antonio Veloso-Fernández. Kimika Fisikoa Saila, Zientzia eta Teknologia Fakultatea FCT/ZTF, Euskal Herriko Unibertsitatea UPV/EHU, Sarriena auzoa, z/g (48940 Leioa, Bizkaia). - antonio.veloso@ehu.eus https://orcid.org/0000-0003-1309-2373

Nola aipatu / How to cite: Aketxe-Bilbao, Eneko Ander; Ruiz-Rubio, Leire; Veloso-Fernández, Antonio (2022). «Matrize polimerikodun konposite magnetikoen sorrera». Ekaia, 42, 2022, 107-125. (https://doi.org/10.1387/ekaia.23001).

Jasotze-data: 2021, uztailak 26; Onartze-data: 2021, irailak 13.

ISSN 0214-9001 - elSSN 2444-3255 / (c) 2022 UPV/EHU

(7) $\odot$ Lan hau Creative Commons Aitortu-EzKomertziala-LanEratorririkGabe 4.0 Nazioartekoa

(c) lizentzia baten mende dago 


\section{SARRERA}

Gaur egungo zenbait arlotan, esate baterako automobilgintzan, komunikazioan, abiazioan, konputazioan edo medikuntzan gertatu den sistema elektrikoen garapen azkarrak propietate egokiak dituzten material konposatuen beharra ekarri du; adibidez, malgutasuna, pisu baxua edo propietate mekaniko, magnetiko eta elektriko interesgarriak dituzten materialak [1]. Gainera, gailu elektriko berrien sorkuntzak komunikazioen maiztasunaren igoera dakar. Adibidez, korronte alternoko motorrak, inprimagailuak, iluminazio-gailuak, komunikazioen instrumentuak eta sistema digitalak, erradiazio elektromagnetikoaren (EMI) oinarrizko iturriak dira, eta gainerako instrumentu elektrikoen funtzionamenduan eragina izan dezakete, eta gailuen funtzionalitatea guztiz hondatu. Interferentzia elektromagnetikoa gertatzen dela esaten da gailu elektronikoetan izaten/gertatzen den maiztasuna interferentziaren antzekoa denean. Horrek dakar urruneko kontroleko gailu elektronikoen funtzionamendua gelditzea, radarren abiadura-detekzio faltsuak sortzea eta, berez, gailu elektronikoen bizitzaren murrizketa. Gainera, sistema elektronikoak eta objektu bizigabeak ez dira EMIren aurrean arazoak pairatzen dituzten bakarrak, giza gorputzek eta sistema biologikoek, EMI aurrean itzeleko arriskuak dituzte: adibidez, tumoreen agerpena. Aurreko urteetan indar-maila hauetan egon ez den erradiazio elektromagnetiko honen aurrean, beharrezkoa da EMIren aurkako babesa eskaini ahal diguten materialetan ikertzea. 1. irudian erakusten da erradiazioaren aurkako babesa nola lor daitekeen EMIen seinalea txikituz. Efektu desberdinak gerta daitezke: islapena, absortzioa edo sakabanatzea. Irudian, EMI erradiazioa gezi hori gisa dago adierazita, eta materialaren aurka jotzean ikusten da nola honek zenbait jokabide izan ditzakeen. Goitik behera azalduz, lehen erradiazio-gezian erreparatuz, ikusten da nola guztiz zeharkatzen duen materiala; beraz, transmisioa gertatzen da (gezi urdin argiarekin adierazita); bigarren erradiazio gezia ikusirik, ikusten da nola erradiazioaren norabidea aldatzen dela, bai materialaren kanpoaldean (islapena, gezi urdina) eta baita barnealdean (uxaketa, gezi berdea) ere; azkenik, gezi laranjak erakusten du nola azken erradiazio-izpia materialaren barnean absorbatzen den (absortzioa) [1].

Andres Orlando Posadaren ikerketa-taldeak EMI izpien aurkako babesmateriala sortzeko moduak ikertu zituen [1]. Hain zuzen, ikertzaileek EMI izpien babesa lortzeko, kautxuzko matrize polimerikodun konpositea erabili zuten. Horietan, nikelezko ferrita partikula ferromagnetikoak barreiatzen ziren. Matrize polimerikoak materialari edozein formatako konpositea lortzeko gaitasuna ematen dio. Emaitzak nahiko onak ziren, baina oraindik babes elektromagnetiko hobea behar zen. Konposite magnetiko hobeak lortzeko, sortzen diren materialek egitura berezia behar dute. Adibidez, matrize polimerikodun sandwitch egitura sortuz eta karbonozko nano-tutuak erabiliz, partikula magnetikoekin batera EMI izpien absortzio handiagoa lortzen zen [1]. 2. irudian, sandwitch egiturako konpositearen eskema adie- 
razten da, non kautxuzko bi xaflak karbonozko nano-tutuen bidez eusten baitira eta metalezko partikula ferromagnetikoak xaflen artean baitaude. Modu honetan, partikula magnetikoek EMI erradiazioa xurgatzen dute.

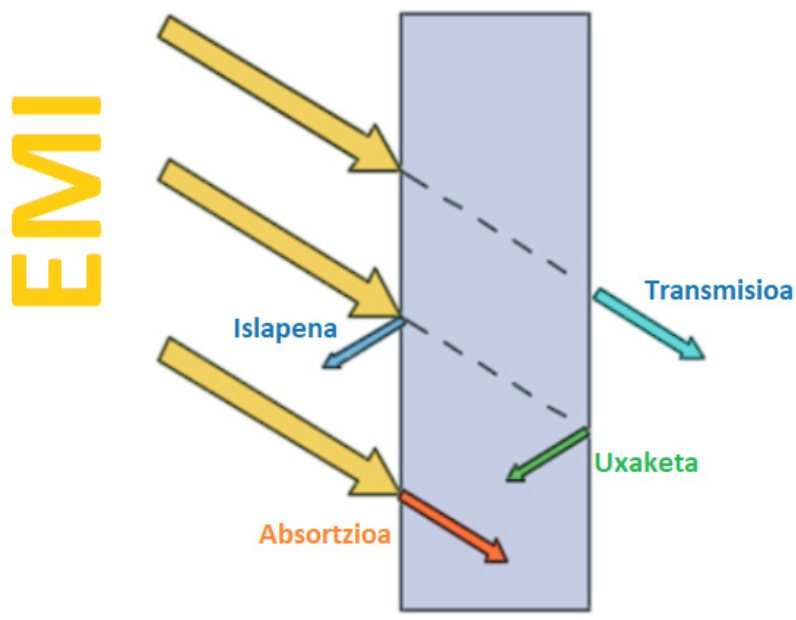

1. irudia. Erradiazio elektromagnetikoaren aurka babesteko moduak.

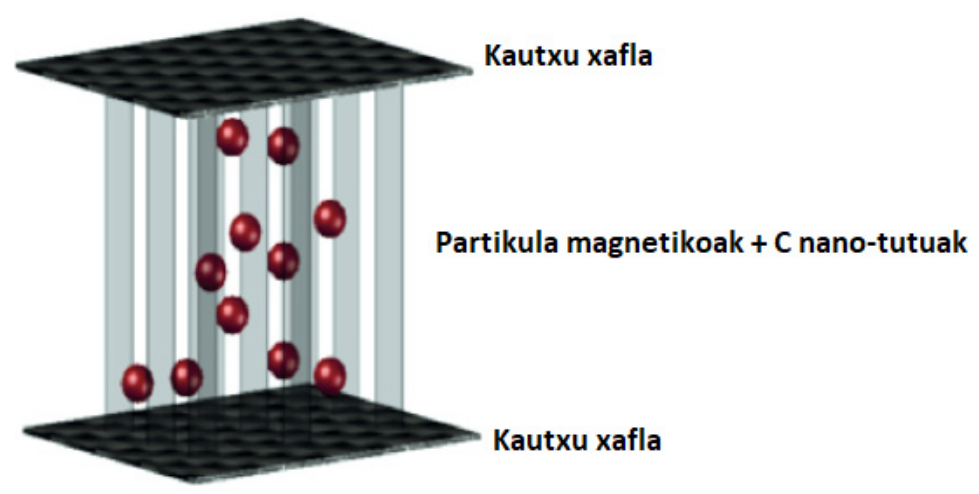

2. irudia. Erradiazio elektromagnetikoaren aurka babesteko konpositearen egitura eskematikoa.

Konposite polimeriko magnetikoek zenbait aplikazio izan dezakete material malguak eta egokiak direlako: esate baterako, mikrotxipak, egitura aeroespazial eta aeronautikoak, urpekaritzarako jantziak, autoak egiteko industriakoak edo kirol-tresnak [2, 3]. Hegazkingintzaren adibide bezala, hegazkinen motorrak zuten iman pisutsuak matrize polimerikodun konpo- 
site magnetikoen ordez aldatu ziren. 2016. urtean Rupinder Singhak burdinez egonkortutako dentsitate txikiko polietileno polimeroak eta dentsitate handiko polietileno polimeroak erabili zituen [3]. 2017. urtean, Carolina Braccini Freirek polietileno tereftalatoa erabili zuen matrizetzat. Bi zientzialari horiek lortutako emaitzak oso antzekoak ziren, eta biek aurkitu zuten burdina barreiatuta egoteak propietate mekanikoen igoera handia dakarkiola konpositeari, bakartutako matrize polimerikoekin alderatuz [3]. Beraz, nahiz eta matrize polimerikoaren erresistentzia mekanikoa hain handia ez izan, burdin partikulak barreiatuz gero, erresistentzia handitu egiten da. Garraiorako erabiltzen diren Boeing 757 (1980. urtean) eta Boeing Dreamliner 787 (2009. urtean) hegazkinek eginkizun horren adibide zehatza dira, non pisuaren $\% 5$ eko eta $\% 50$ eko jaitsierak frogatu baitziren.

Konposite magnetiko hauen aplikazio ugariak ikusirik, lan honetan konposite magnetiko bat garatuko da. Hain zuzen, ikerketa honen helburua da material baten gainazalaren forma kontrolatzea. Horretarako erabili den materiala, matrize polimerikodun eta barreiatutako fase gisa, partikula magnetikoak dituen material konposatua sortzea da. Modu horretan, material hau eremu magnetiko baten menpe jarriko da, eta haren gainazaleko forma aldatu ahal izango da. Konposite hauek errota eolikoetan aplika daitezke. Errota eolikoen helizeen gainazala eremu magnetiko batekin eralda baldin badaiteke (eremua erroten paletatik sortuz), gainazaleko itxura ere alda genezake, eta haizeak nondik jotzen duen, horren arabera energia ateratzeko eraginkortasuna igo genezake, haizeak nondik jotzen duen, horren arabera 3. irudiko olatu itxuradun gainazal horien norabidea kontrolatu ahal dugulako, eta marruskadura-indarra hobeto aprobetxatuko genukeelako. Azken baten haizeak pala mugitzen du marruskadura indarrari esker.

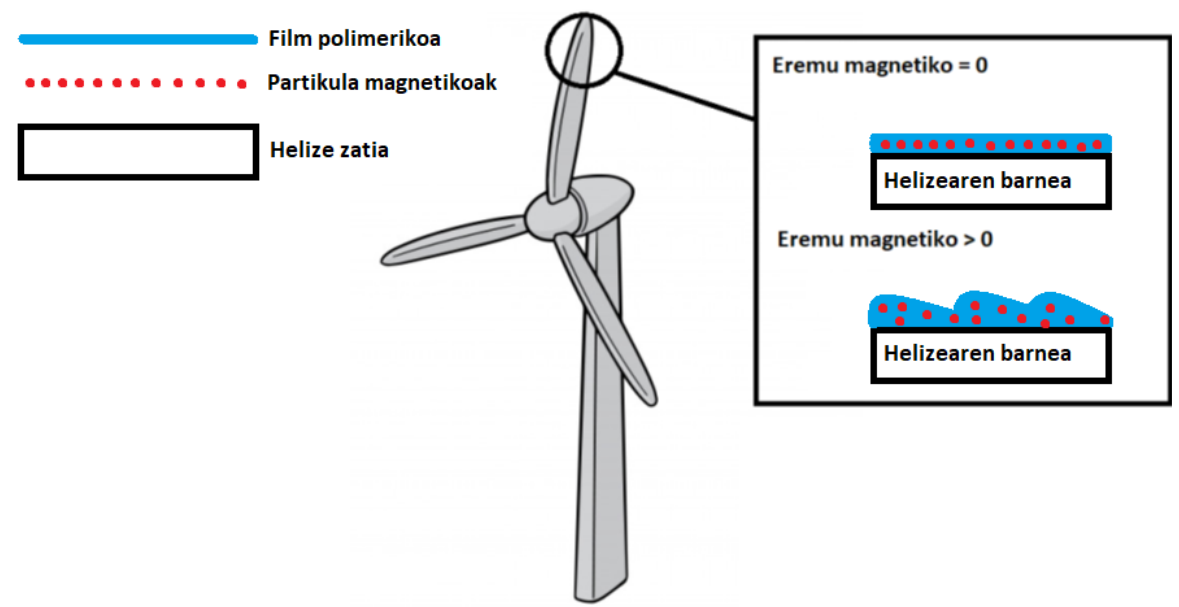

3. irudia. Errota eolikoa, helizeen gainazala film magnetikoekin estalita. Gainazalak eremu magnetiko baten menpe film polimerikoaren eraldaketa erakusten du. 
3. irudiaren handipenean eskematikoki erakusten da nola, errota eoliko baten helizea konposite magnetiko batez estalita egonik, eremu magnetiko bat aplikatzean azaleraren itxura aldatzen den. Horretarako, sortuko den konpositearen matrizea poliuretano bat izango da; eta, barreiatutako fase gisa, partikula magnetikoak izango dira, hain zuzen, kobaltozko ferritak.

\section{PROZEDURA ESPERIMENTALA}

Atal honetan sortu diren partikula magnetikodun konpositeen sintesia azaltzen da, bai eta konposite haiei egindako karakterizazioa ere. Gure material konposatuaren matrizea poliuretanoa da; beraz, lehendabizi matrize optimo bat bilatu behar da. Behin matrize optimoa aukeratuta, partikula magnetikoen gehitzeari ekingo diogu, eta, ondo barreiatzen badira, karakterizatu egingo dira.

\subsection{Poliuretanoak}

Lehendabizi poliuretano (PU) onena aukeratu da (hau da, elastikoena eta zatitzeko gogorrena), nahi dugun material konposatuaren matrizea izan dadin. Poliuretanoa sortzeko, hiru konposatu behar dira: poliol bat, isozianato bat eta kate hedatzaile bat. Hain zuzen, poliol gisa pisu molekular desberdineko politetrametileneterglikola frogatu dira $(250,650$ eta $1.000 \mathrm{~g} / \mathrm{mol})$. Isozianato bezala, hexametileno diisozianatoa erabili da, $168,19 \mathrm{~g} / \mathrm{mol}$ pisu molekularrekoa eta $1,047 \mathrm{~g} / \mathrm{cm}^{3}$ dentsitatekoa. Azkenik, kate hedatzaile gisa errizino-olioa erabili da, $933,4 \mathrm{~g} / \mathrm{mol}$ pisu molekularrekoa eta $0,961 \mathrm{~g} / \mathrm{cm}^{3}$ dentsitatekoa [4].

Erabilitako hiru erreaktiboak, poliola: diisozianatoa: kate hedatzailea, 1: 2: 1 estekiometriarekin erabili ziren. Sintesi guztiak bi etapako metodoaren bidez egin ziren,4. irudian ikus daitekeen bezala. Lehen etapan PTMG eta HDI nahasten dira, eta aurrepolimeroa sortzen da. Bigarren etapan, kate hedatzailea gehitzen da, eta sare polimerikoaren zabalkuntzarekin dago lotuta. Behin poliuretano-nahastea izanik, tratamendu termikoa burutu behar da, poliuretano sarea modu egokian ontzeko, hau da, likido likatsu bat izatetik solido elastiko batera bilakatzeko. Aurrepolimeroa sortzeak eta tratamendu termikoa burutzeak katalizatzailearen erabilpena ekiditea baimentzen digu [5]. Irudi berean ikus daitekeen bezala, sintesiaren lehen etapetako baldintzak finkatu dira lehenik eta behin, erreakzioa $70^{\circ} \mathrm{C}$-tan eta bi orduz mantenduz [6,7]. Ondoren, aurrepolimeroa sortuta, bigarren etapetako baldintzak finkatu ziren, behin kate hedatzailea gehituz, tenperatura berean 30 minutuz mantenduz. Behin erreakzioa bukatuta, 24 orduko tratamendu termikoa egin zitzaion prentsa batean, $100 \mathrm{~kg} \cdot \mathrm{cm}^{-2}$-ko presiopean eta $100^{\circ} \mathrm{C}$-ko tenperaturan. Tratamendu termikoaren denbora osoa igaro eta gero, erreakzioa amaitutzat ematen da, eta, prentsa hoztuz, poliuretanozko xaflak eskuratu dira [8]. 


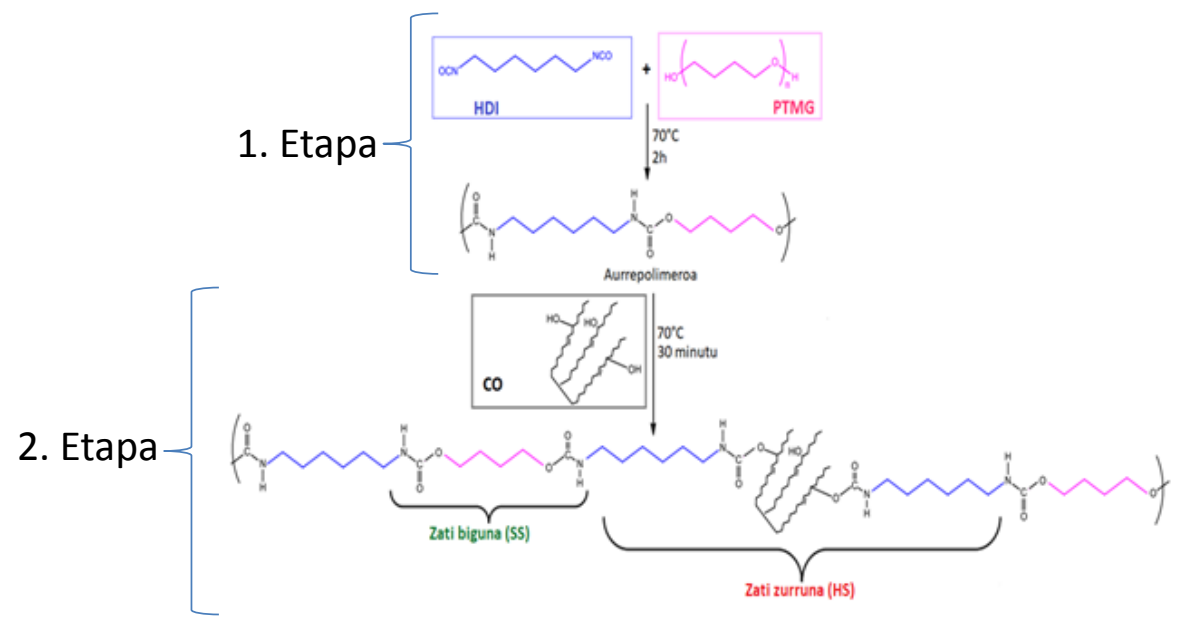

4. irudia. Poliuretanoen bi etapetako sintesia: PTMG, HDI eta CO erreaktiboak erabiliz.

\section{2. $\mathrm{CoFe}_{2} \mathrm{O}_{4}$ partikula magnetikoak}

Ikerketa honetan erabili diren partikulak, partikula magnetiko ferromagnetikoak izan dira, kobaltozko ferritak $\left(\mathrm{CoFe}_{2} \mathrm{O}_{4}\right)$, hain zuzen. Material ferromagnetikoek eremu magnetiko indartsuak sortzen dituzte. Garrantzitsuenak burdina $(\mathrm{Fe})$, kobaltoa $(\mathrm{Co})$ eta nikela $(\mathrm{Ni})$ dira. Propietate ferromagnetikoak sare kristalinoan dauden barne-elektroi ez-parekatutako elektroien spinak lerrokatzen diren moduaren araberakoak dira. Atomo bakartien barne-geruzak kontrako spina duten elektroi bikoteekin betetzen dira, eta modu honetan ez da inolako momentu dipolar magnetikorik geratzen. Solidoetan, balentzia elektroiak bata bestearekin parekatzen dira, eta lotura kimikoak sortzen dira, modu honetan ez da inolako momentu magnetikorik geratuko elektroi hauei esker. Burdina, kobalto eta nikelean $3 \mathrm{~d}$ barne-elektroiak elementu hauek erakusten duten ferromagnetismoaren sortzaileak dira. Burdinak 3d orbital geruzan lau elektroi ez-parekatu ditu, kobaltoak hiru eta nikelak bi. Giro-tenperaturan, Fe, Co edo Ni lagin solido batean, atomoen $3 \mathrm{~d}$ elektroien spinak paraleloki lerrokatzen dira, imanazio espontaneoa deritzon eraginaren bidez. Dipolo magnetiko atomikoen lerrokatze paralelo hauek domeinu magnetiko deritzon eskualde mikroskopikoetan soilik gertatzen dira. Domeinu hauek zoriz orientatuta badaude, orduan ez da imanazioa gertatuko [9].

Erabilitako partikulek (NAM industriak bidalitakoak) $5,3 \mathrm{~g} \cdot \mathrm{ml}^{-1}$ dentsitatea eta 35-55 nm-ko tamaina dute; beraz, nanopartikulak dira. Oso erabiliak diren partikulak dira, bere anisotropia magnetikoagatik, 
saturaziozko magnetizazio altuagatik eta kimikoki oso egonkorrak direlako. Partikula mota hauek duten egitura espinela inbertsoa da (5. irudia), hau da, bi aurpegietan zentratutako sare kubikoa; zeinean $\mathrm{Fe}(\mathrm{III})$ ioiek gune tetraedrikoak betetzen baitituzte eta oktaedrikoen erdialdea baitira; bestalde, Co(II) ioiek gainerako gune oktaedrikoak betetzen dituzte [10].
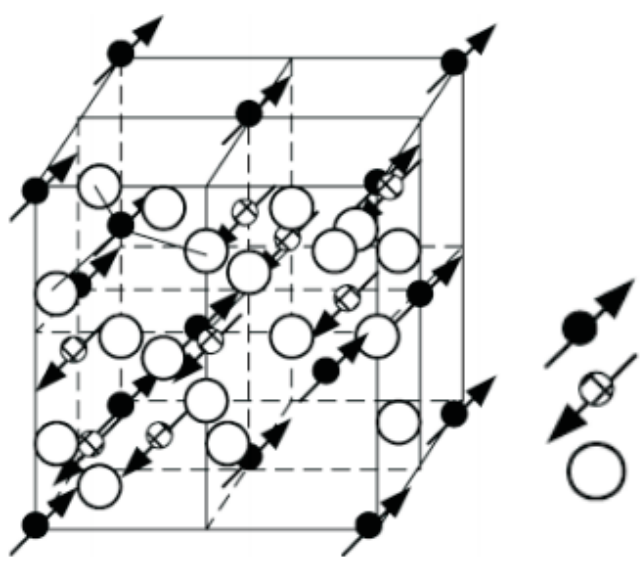

\section{A: Hutsune tetraedriko \\ B: Hutsune oktaedriko \\ O: Oxigeno anioiak}

5. irudia. Kobaltozko ferritaren sare kristalinoa. Goranzko geziek hutsune tetraedrikoak adierazten dituzte, beheranzko geziek hutsune oktaedrikoak eta biribilek oxigenoak betetzen dituzten lekuak [11].

\subsection{Konpositeak}

Aurreko atalak kontuan hartuz, lan honetan sortuko diren konpositeak bi fase izango ditu: poliuretanoa matrize gisa eta kobaltozko ferriten nanopartikulak barreiatutako fase gisa. Beraz, matrize polimerikoaren polimerizazio-eraketaren urratsaren momentu batean partikula magnetikoak gehitu behar izango dira, hau da, poliuretanoaren sintesian (4. irudia) oinarritu beharko gara. 6. irudian ikus daitekeen bezala, sintesian hiru momentu ezberdinetan gehitu ahal izango dira partikulak: (1) partikulak poliolarekin eta diisozianatoarekin nahasten direnean; (2) partikulak kate hedatzailearekin nahastuz; eta azkenik, (3) partikulak azken momentuan nahastuz, behin poliuretanoaren hiru osagaiak erreakzionatu dutenean.

Hiru bide hauen arteko konparazioa eginez, hirugarren bidea, hau da, partikulak azken momentuan gehitzearen bidea, emaitzarik onenak ematen dituena da. Izan ere, lehen eta bigarren bideak erakutsitako emaitzetan, nahiz ez diren guztiz txarrak izan, partikulen homogeneotasuna matrizean zehar ez da hain ona izan. 


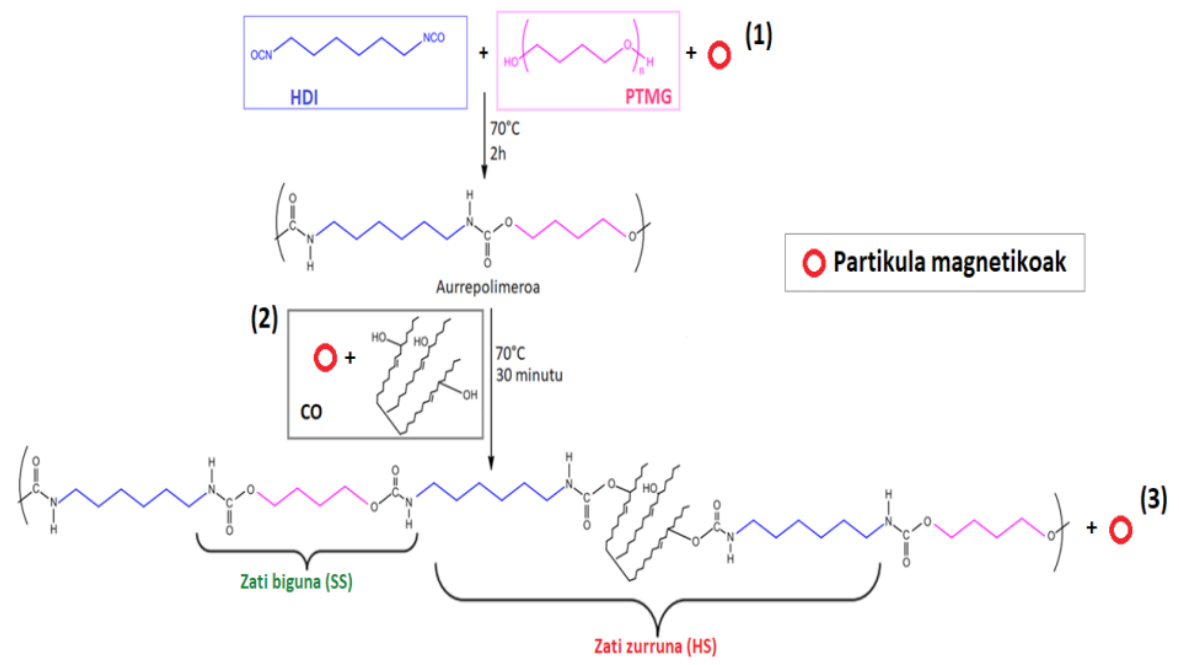

6. irudia. Sintetizatutako poliuretanoaren eskeman, partikulak noiz gehitu daitezkeen adierazita. (1) Lehen bidea, partikulak hasierako nahastean gehitu. (2) bigarren bidea, partikulak kate hedatzailearekin nahastu. (3) hirugarren bidea, partikulak azken urratsean gehitu.

Beraz, behin konposite-nahastea molde barruan eta tefloizko bi gainazalen artean dagoelarik (tefloiak poliuretanoa plaka metalikoetan itsastea ekiditen du), bi plaka metalikoen artean sartu eta zuzenean prentsa hidraulikora eraman da. Prentsa hidraulikoan, 100 Pa-ko presioa eta $100^{\circ} \mathrm{C}$-ko tenperatura ezarri eta 24 orduz uzten da konpositea guztiz solidotu arte.

\subsection{Karakterizazio-teknikak}

\subsubsection{Trakzio-probak}

Matrize optimoaren bilaketan adierazi den bezala, pisu molekular desberdineko PTMG-k erabili ziren, eta jakiteko zeinek ematen zituen film elastikoena, malguena eta hausten gogorrena, PTMG bakoitzeko filmei froga mekanikoa egin zitzaien, hain zuzen, trakzio-froga. Hau da, karakterizazio hau poliuretanozko matrize polimerikoei egin zitzaien, ez partikula magnetikodun konpositeei. Karakterizazio hori egiteko, MTE-1 textuorometroa erabili zen (7. irudia). Tresna honek egiten duena da lagin bakoitzeko probeta bat kontrako bi alde desberdinetatik luzatu, hautsi arte. Beste era batera esanda, laginaren luzapenak (ehunekotan) eta aplikatzen zaion indarrak zeharkako azalerarekiko $\left(\mathrm{N} \cdot \mathrm{m}^{-2}\right)$ erlazionatzen ditu. 


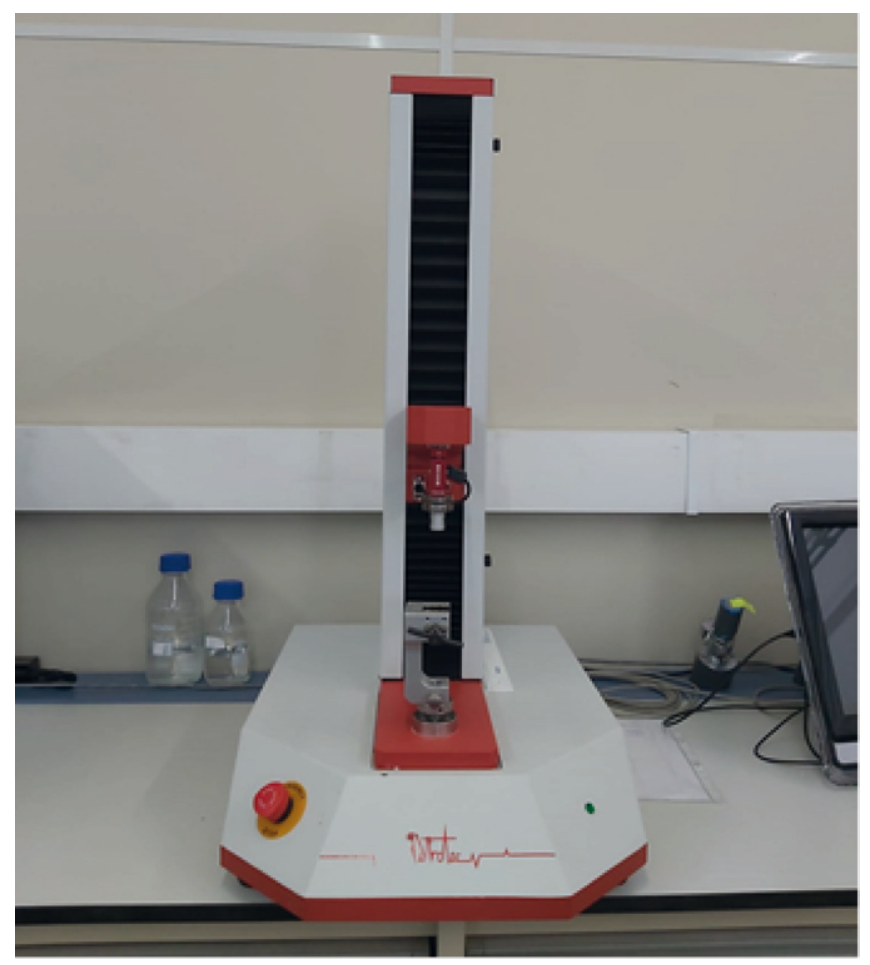

7. irudia. Trakzio frogarako erabilitako testuorometroa.

\subsubsection{Ekorketazko kalorimetria diferentziala}

Ekorketazko kalorimetria diferentzial azterketa edo differential scanning calorimetry (DSC) erabiliz, laginak jasaten dituen trantsizio termikoak determinatzen dira. Trantsizio horiek, poliuretanoen kasuan, haien zati gogorraren eta zati bigunaren arteko erlazioarekiko zuzenki proportzionalak dira. Neurketa hau aurrera eramateko, Mettler Toledo DSC 822 $2^{\mathrm{e}}$ kalorimetroa erabili zen (8. irudia). Karakterizazio honek erlazioan jartzen du materialaren egiturak xurgatzen duen beroa gramoko eta materialari aplikatzen zaion tenperatura. Tenperatura baxuetan eta altuetan matrizeak izango duen egitura desberdina izango da, eta xurgatzen duen beroa ere bai. Beraz, DSC kurbatik beira trantsizio tenperatura $\left(\mathrm{T}_{\mathrm{g}}\right)$ determinatzea lortzen da $[2,12]$. Modu horretan, partikula magnetikorik gabeko poliuretanoaren egitura tenperatura desberdinetan, partikula magnetikoen ondorioz ea aldatzen den aurresateko aukera emango digu. Hau da, karakterizazio honek erakutsiko digu ea partikula magnetikoek matrize polimerikoaren egituran aldaketak sortzen dituzten ala ez. 


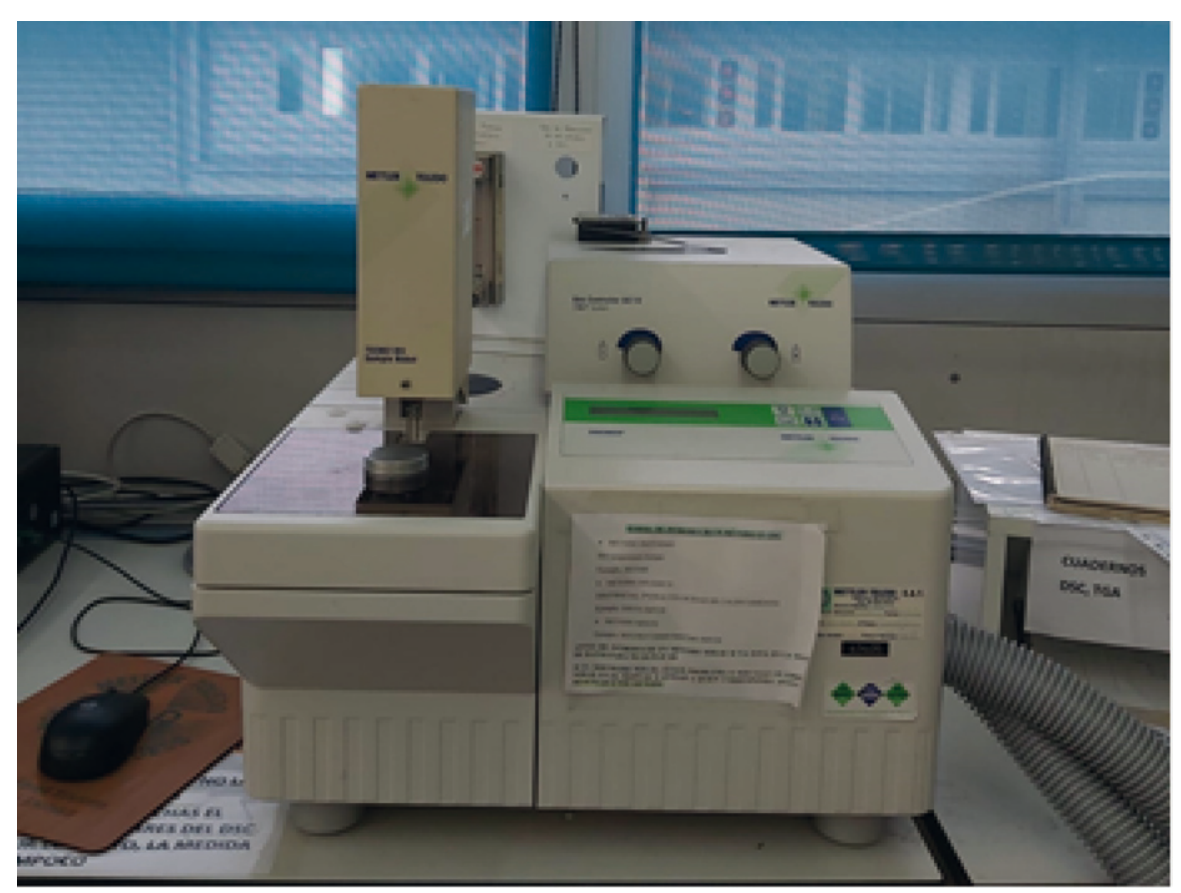

8. irudia. Ekorketazko kalorimetria diferentzialeko tresna.

\subsubsection{Lagin bibrazionaleko magnetometria}

Lagin bibrazionaleko magnetometria edo vibrating sample magnetometer (VSM) deritzon teknika erabili zen sortutako konpositeen propietate magnetikoak aztertzeko. 9. irudian ikus daitekeen bezala, VSMak eremu magnetiko baten barnean bibratzen dagoen lagin baten imanazioa ematen du. VSMren erdialdean lagina jartzen da, eta elektromagnetometroak indar ezberdineko eremu magnetikoak aplikatzen ditu. Eremu magnetiko horiek aurretik aipatu diren partikula magnetikoen orbitalen azken geruzetako spinak mugiaraziko dituzte. Alboetako lau sentsoreek spin mugimendu horiek detektatuko dituzte, eta, bibrazioari ezker, spin mugimendu hauek uhin elektriko gisa kuantizatuko dituzte. Uhin elektriko hauek, transformadore bati esker, konposatuaren imanazioa emango dute. Modu honetan, konposite bakoitzaren imanazioak lortu dira eremu magnetiko zehatz baten aurrean, hau da, histeresi-kurbak [13]. 


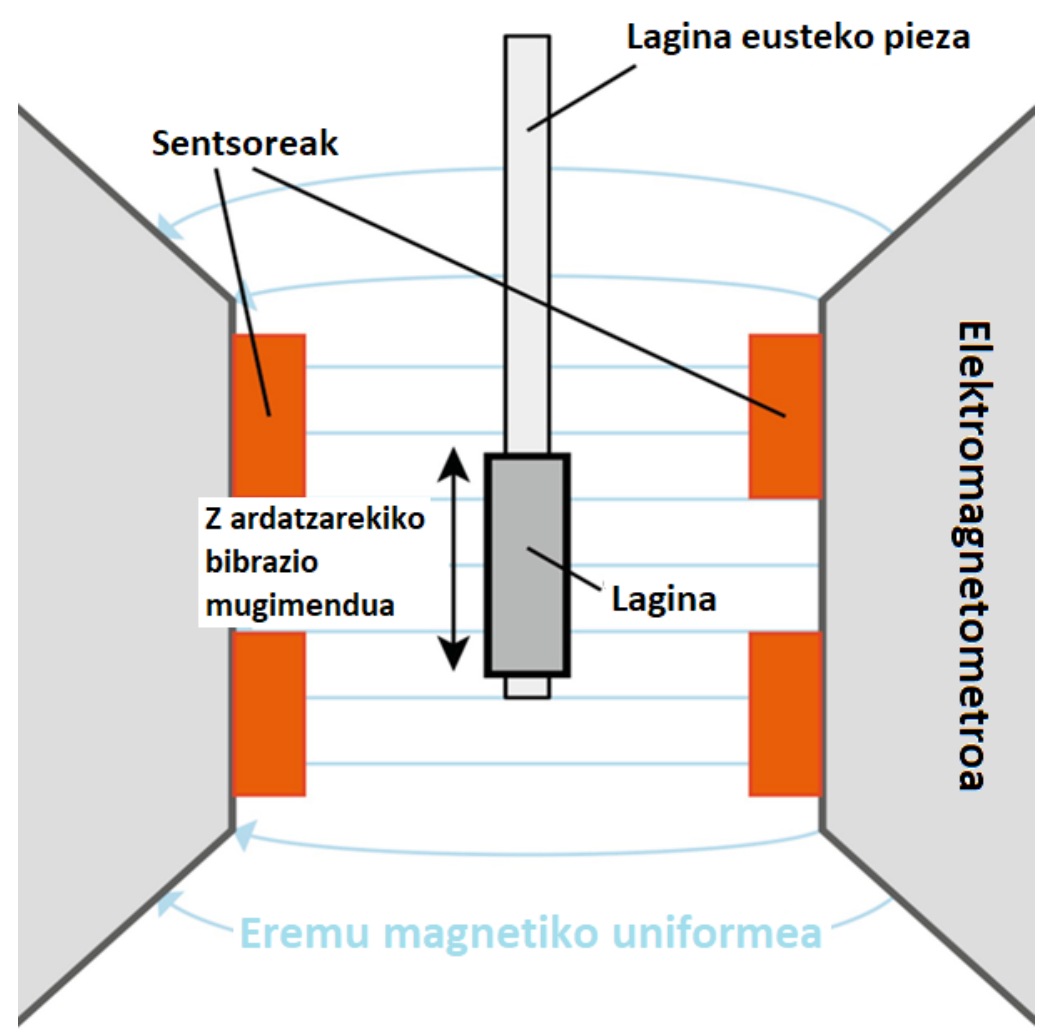

9. irudia. VSM funtzionamenduaren irudi eskematikoa.

Ikerketa honetan erabilitako partikulak ferromagnetikoak izan direnez, lan honetan histeresi-kurba ferromagnetikoak sortu dira. Aipatu behar da ferromagnetismoa magnetismo mota indartsuena eta garrantzitsuena dela. Ferromagnetikoak imanak deritzen materialak dira, iman iraunkorrak erakartzen dituelako [13].

10. irudian ikusi daitekeen bezala, histeresi-kurba bat sortzeko, material ferromagnetikoari fluxu magnetiko $(\mathrm{H})$ desberdinak aplikatzen zaizkio eta fluxu bakoitzarentzat agertzen diren imanazio (M) desberdinak neurtu behar dira.

Ezaugarri garrantzitsuena da kurba ez dela lineala, eta jokabidea ez dela alderantzizkoa. Alderantzizkotasun falta, histeresi magnetikoa deritzo. 10. irudian oinarrituz, hasteko, ikusten da nola $\mathrm{H}$ igoz gero imanazioa balio maximo batera hurbiltzen dela gradualki, saturaziozko imanazioa deritzona $\left(\mathrm{M}_{\mathrm{S}}\right)$. Saturaziozko imanazioa oso garrantzitsu den propietatea da material ferromagnetiko batean, eta propietate intrintsekoa da, hau da, ber- 
bera dela edozein zatitan eta ez dago materialaren prozesatze-historiaren menpe. Jarraitzeko, aplikatutako eremu magnetikoaren intentsitatea txikitzean, imanazioaren balioak ez dira aurrekoetara bueltatzen. Imanazioaren balioa $\mathrm{H}$ berriro zero baliora bueltatzen denean, hondarreko imanazioa $\left(M_{R}\right)$ deritzo. Saturaziozko imanazioa $\left(M_{S}\right)$ ez bezala, hondarreko imanazioa materialak izan duen tratamenduaren menpe dago; izan ere, haren egiturak eta haren domeinu magnetikoen paretek akats desberdinak izan ditzakete (pikorrak, inklusioak eta abar) [13]. Hondarreko imanazio handia duten materialak ferromagnetiko gogorrak dira. Hondarreko imanazio txikia dutenak, berriz, ferromagnetiko ahulak dira. Ondorioz, nahiz eta $\mathrm{H}$ zerora bueltatzean imanazio ferromagnetiko baten balioa zero izatera ez bueltatu, ez du esan nahi imanazioa zerora bueltatu ezin denik. H eremu magnetiko baten intentsitatea alderantzizko norabidean ezarriz, imanazioa zero baliora eraman daiteke. Imanazioa zero baliora bueltatzeko behar den $\mathrm{H}$ balioari eremu hertsatzailea $\left(\mathrm{H}_{\mathrm{C}}\right)$ deritzo. Eremu hertsatzailea ez da propietate intrintsekoa, eta $\mathrm{H}_{\mathrm{C}}$ balioa eremu aldaketaren abiaduraren eta anisotropia bezalako faktoreen menpe dago, sakonduko ez ditugun faktore batzuen menpe. Eremu hertsatzailearen magnitudeak ezartzen du materialaren erabilgarritasuna aplikazio ezberdinetan. Aurreko urrats hauei jarraituz, 10. irudiko $\mathrm{Y}$ ardatzarekiko balio positiboentzat lortu ditugu saturazioa $\left(M_{S}\right)$, hondarreko imanazioa $\left(M_{R}\right)$ eta eremu hertsatzailea $\left(H_{C}\right)$. $Y$ ardatzarekiko grafiko zati negatiboa lortzeko prozedura berbera erabiltzen da, baina oraingo honetan poloak inbertituta daude (gogoratu behar dugu magnetismoa bi polo naturaletan oinarritzen dela) [13].

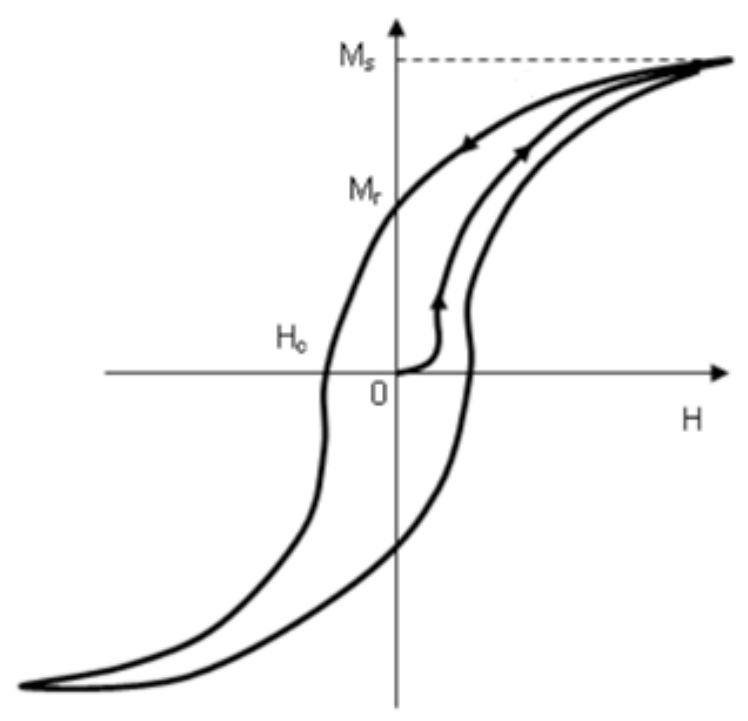

10. irudia. Material ferromagnetiko batek sortzen duen imanazio-kurba tipikoa. 


\section{EMAITZAK ETA EZTABAIDA}

Atal honetan, lehenik eta behin, matrize optimoaren aukeraketa azalduko da. Horretarako, poliuretano ezberdinen arteko trakzio-frogaz baliatu gara. Behin matrize optimoa zein den jakinda, konposite magnetikoak sortu eta azalduko dira. Azkenik, sortutako konposite horien propietateak determinatzeko burutu diren karakterizazio-teknikak azalduko dira, eta karakterizazio-emaitzetan sakonduko da.

\subsection{Matrizearen trakzio-froga}

Matrize polimeriko optimo bat bilatzea zen lehendabiziko helburua, hau da, elastikotasun aproposa eta hausturarekiko erresistentzia altuko matrizea aurkitzea poliuretano (PU) bat erabilita. Horretarako erabilitako hiru erreaktiboak, poliola: diisozianatoa: kate hedatzailea, 1:2:1 estekiometriarekin erabili dira.

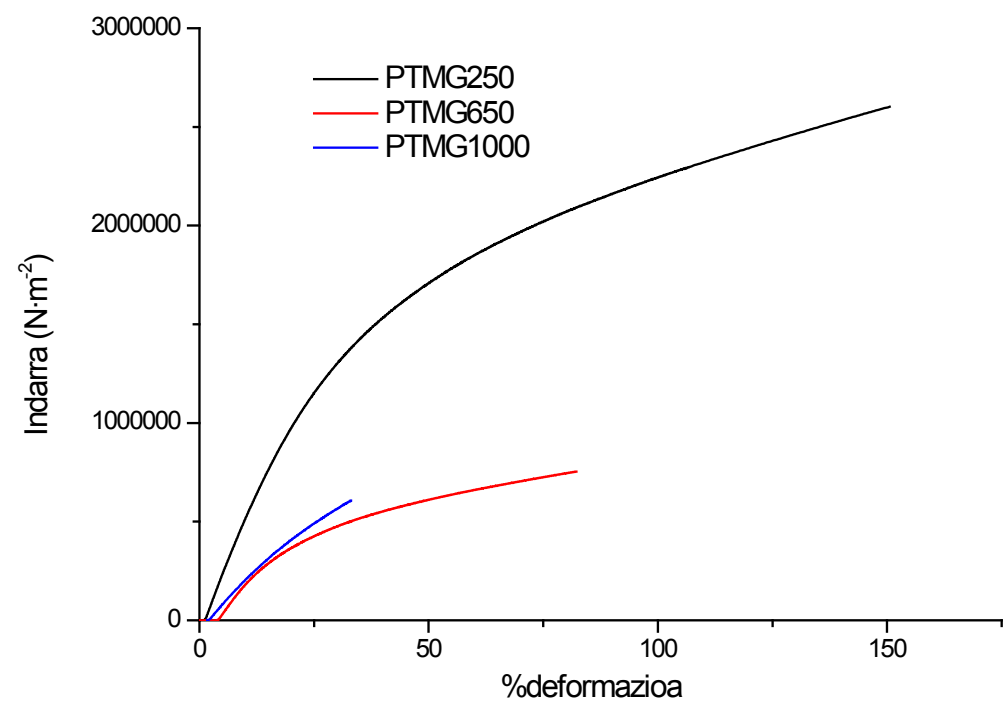

11. irudia. Trakzio-froga PU film mota bakoitzarentzat. Laginari aplikatutako zeharkako indarra $v s$ deformazioa ehunekotan.

Filmak ahalik eta elastikoenak behar dira, baina erresistenteak ere izan behar dira. Baldintza hauetara ondoen egokitzen zen filma PTMG-250 zen. PTMG-1000-k eskaintzen zigun hausturarekiko erresistentzia oso urria zen, berehala apurtzen zelako trakzio-indar minimo baten eraginez. Antzeko gauza gertatzen zen PTMG-650-ren erresistentziarekin. Hori oso argi ikusten da 8. irudiari erreparatuz. Irudiko grafikoak adierazten digu zenba- 
teko indarra egin behar den film bakoitza deformatzeko eta hausteko. Maldak bere elastikotasuna adierazten du, hau da, zenbat eta malda handiagoa izan, elastikotasuna baxuagoa izango da (deformatzeko indar handiagoa behar duela esan nahi duelako). 11. irudian, kurba bakoitzaren azken puntuak haustura gunea adierazten digu, hau da, lagina zenbateraino luza daitekeen apurtu aurretik. Beraz, nahiz eta PTMG-250-ko filmen elastikotasuna hain altua ez izan (gainerako biekin alderatuz), askoz gehiago luza daiteke hausturara heldu gabe.

\subsection{Konposite magnetikoen sorrera}

Behin jakinik matrize optimoa PTMG-250 erabiliz lortzen zela, konpositeen matrizea izanik, film magnetikoak prestatu ziren. Kobaltozko burdinazko nanopartikulak erabiliz, lau sintesi ezberdin burutu ziren bolumenean $\% 2,5, \% 5, \% 7,5$ eta $\% 10$ nanopartikulak izanda.

Kontuan izan behar da matrizea malgua izan daitekeela, baina konpositeak ez duela zertan malgua izan. Adibidez, 12. irudian bi konposite desberdinak erakusten dira. 12.a. irudian ikusten den bezala, \%10eko nanopartikulazko konpositea ez da elastikoa, eta hauskorra da; beraz, iman bat hurbilduz gero, zuzenean itsasten da eta konpositea apurtu egiten da. Ordea, 12.b. irudiari erreparatuz, ikusten da nola, partikulen ehunekoa 2,5era jaitsiz, matrize polimerikoaren izaera ez dela desagertzen, eta propietate malgu eta elastikoa mantentzen dela, guztiz magnetikoa izanik.

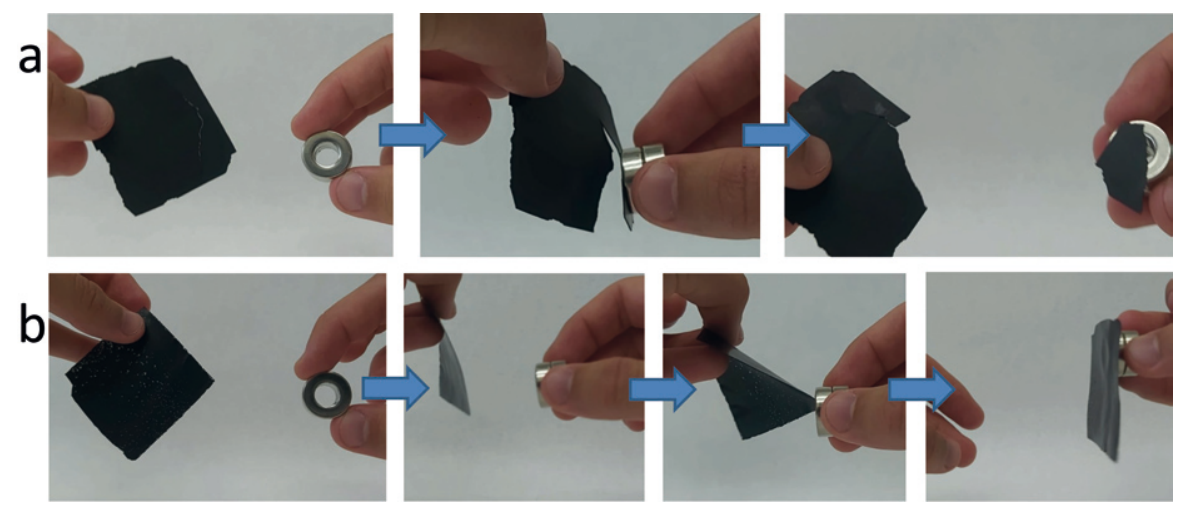

12. irudia. Konposite magnetikoek itxura biribileko iman sendo baten aurrean erakusten duten portaera, partikulen ehunekoa a) \%10a eta b) \%2,5a izanik.

\subsection{Konpositeen ekorketazko kalorimetria diferentziala}

Kalorimetria burutzearen arrazoia, gure matrize polimerikoaren (PUren) beira-trantsizioa partikulen eraginez aldatzen zen ala ez jakitea 
zen. Modu horretan jakin dezakegu konpositeen malgutasunak $0^{\circ} \mathrm{C}$ azpiko zer tenperaturaraino mantenduko den. Horretarako, partikula gabeko poliuretanoaren DSCa egin zen, zuri gisa. Ondoren, gainerako film magnetiko guztien kalorimetriak burutu ziren. Kalorimetria-ekorketen emaitzak, 1. taulan laburtzen dira, eta 13. irudian oinarritzen dira.

1. taula. DSC karakterizazioan lortutako emaitzak.

\begin{tabular}{cccc}
\hline Froga & Partikulak & $\%(\mathrm{v} / \mathrm{v})$ & $\mathrm{T}_{\mathrm{g}}\left({ }^{\circ} \mathrm{C}\right)$ \\
\hline 1 & - & - & $-25,27$ \\
\hline 2 & & 2,5 & $-36,61$ \\
3 & & 5,0 & $-37,25$ \\
4 & $\mathrm{CoFe}_{2} \mathrm{O}_{4}$ & 7,5 & $-42,01$ \\
5 & & 10,0 & $-55,61$ \\
\hline
\end{tabular}

Lehen frogan $\mathrm{CoFe}_{2} \mathrm{O}_{4}$ partikularik gabeko konpositeari dagokio, hau da, poliuretanoa edo zuria. $\mathrm{CoFe}_{2} \mathrm{O}_{4}$ nanopartikuladun konpositeen $\mathrm{T}_{\mathrm{g}}$-ak oso ezberdinak dira zuriarekin alderatuta. Hain zuzen, beira-trantsizioa nabarmen jaisten da, eta, lan honen helburua konpositeak edozein tenperaturatan ahalik eta malguen izatea denez, eragin ona da, emaitza hauek tenperatura baxuagoetan malgutasuna mantentzeko gaitasuna erakusten dutelako. Beraz, partikula hauek eragin handia dute beira-trantsizioan, partikula nanoen tamainakoak direlako eta sare polimerikoan barreiatzeko gaitasun handia dutelako. Gainera, partikula hauen kontzentrazioa igoz gero, tarteen balioak ere gradualki igotzen dira. Adibidez, 1. taulan 4 eta 5 frogei erreparatuz, \%10 balio tartea, \% 7,5 balioarena baino negatiboagoa da. Horrek esan nahi du, partikulen presentzia gero eta altuagoa izanda, konpositeak egoera likatsu batetik egoera amorfo zurrun batera igarotzeko tenperatura txikiagoa izan behar dela. Hau da, partikulen presentziak egiten du tenperatura baxuagoetan polimeroaren izaera deformagarria mantendu ahal izatea. 13. irudian oso argi ikusten da zuzen bakoitzak malda-aldaketa bat duela. Malda aldaketa horiei erreparatuz, ikusten da tenperatura desberdinak direla. Hau da, $\mathrm{T}$ berdinetan poliuretano bakoitzak bero kantitate desberdina xurgatzen du. Bero kantitatearen xurgapen horrek, egiturak ezartzen ditu, ondorioz, beira-egitura ezberdina dute haien artean. Beste barik, partikulek eragina dute egitura kristalinoan. 


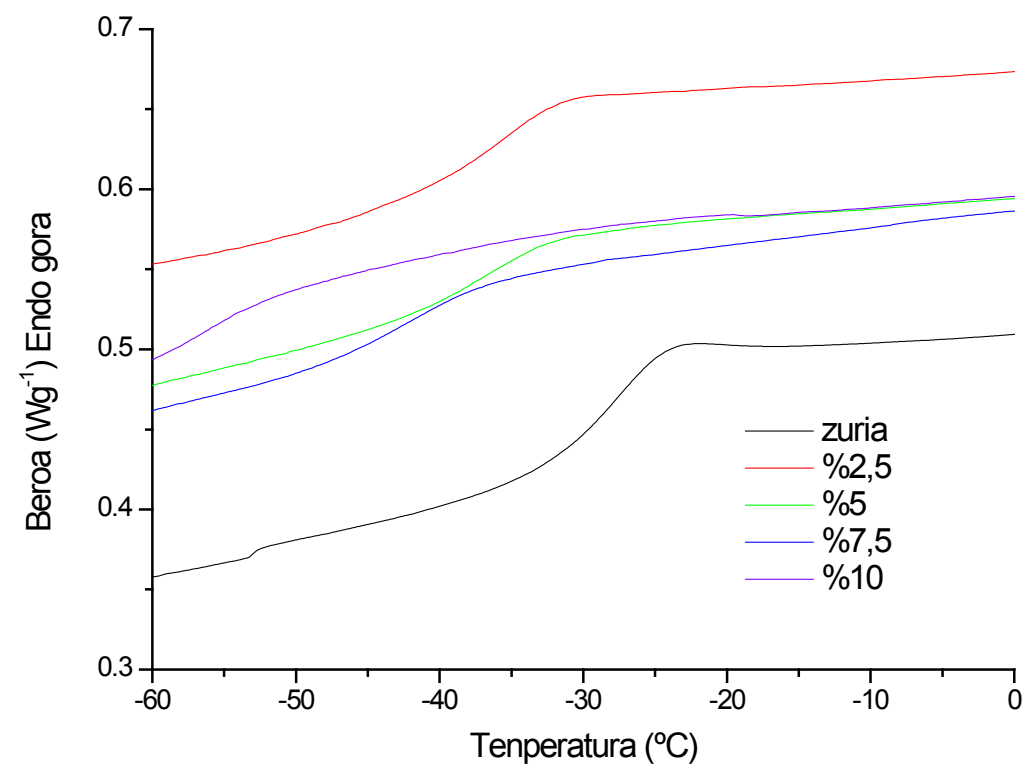

13. irudia. DSC grafikoak: PU partikularik gabe (zuria) eta ehuneko desberdineko $\mathrm{CoFe}_{2} \mathrm{O}_{4}$ nanopartikuladun PU konpositeak.

\subsection{Konpositeen lagin bibrazionaleko magnetometria}

Konposite magnetikoak eremu magnetiko baten aurrean nolako jokabidea duten ikertzeko, magnetometria egin zen. Emaitza horien balio numerikoak 2. taulan adierazita daude, eta 14. irudiko grafikoetatik atera dira, hau da, sortutako $\mathrm{CoFe}_{2} \mathrm{O}_{4}$ partikuladun film mota bakoitzak 14. irudian ikus ditzakegun histeresi-kurbak eman zituen.

2. taula. VSM karakterizazioan lortutako emaitzak.

\begin{tabular}{ccccc}
\hline Froga & Partikulak & $\%(\mathrm{v} / \mathrm{v})$ & $\begin{array}{c}\mathrm{M}_{\mathrm{S}} \\
\left(\mathrm{A} \cdot \mathrm{m}^{2} \cdot \mathrm{kg}^{-1}\right)\end{array}$ & $\begin{array}{c}\mathrm{M}_{\mathrm{R}} \\
\left(\mathrm{A} \cdot \mathrm{m}^{2} \cdot \mathrm{kg}^{-1}\right)\end{array}$ \\
\hline 1 & & 2,5 & 6,96 & 3,45 \\
2 & & 5,0 & 13,73 & 7,67 \\
3 & $\mathrm{CoFe}_{2} \mathrm{O}_{4}$ & 7,5 & 16,88 & 10,02 \\
4 & & 10,0 & 24,65 & 13,89 \\
\hline
\end{tabular}

Histeresi-kurbei dagokienez, zenbat eta bolumenean partikula kantitate gehiago izan, saturaziozko imanazioa $\left(\mathrm{M}_{\mathrm{S}}\right)$ altuagoa izango zen, hau 
da, zenbat eta partikula gehiago izan, izaera magnetiko handiagoa eta imanazio altuagoa izango zuen. Partikula magnetiko gehiago izanez gero, imanaren indarra gero eta handiagoa izango da. Hondarreko imanazioei erreparatuz, hondarreko emaitza altuak ditugu, hau da, $M_{R}$ denak $M_{S}$ balioen erdia baino altuagoak dira; beraz, partikula hauek izaera ferromagnetiko altua dute. Horrek esan nahi du konposite ferromagnetiko sendoak direla, hau da, iman iraunkorrak direla eta eremu magnetiko baten aurrean oso sentikorrak direla. Horri esker, imanazio indartsua dute, eta izaera hori ez da desagertuko. Beraz, jokabide honi esker konposite hauek metaletan eta imanetan itsasteko propietatea dute [13].

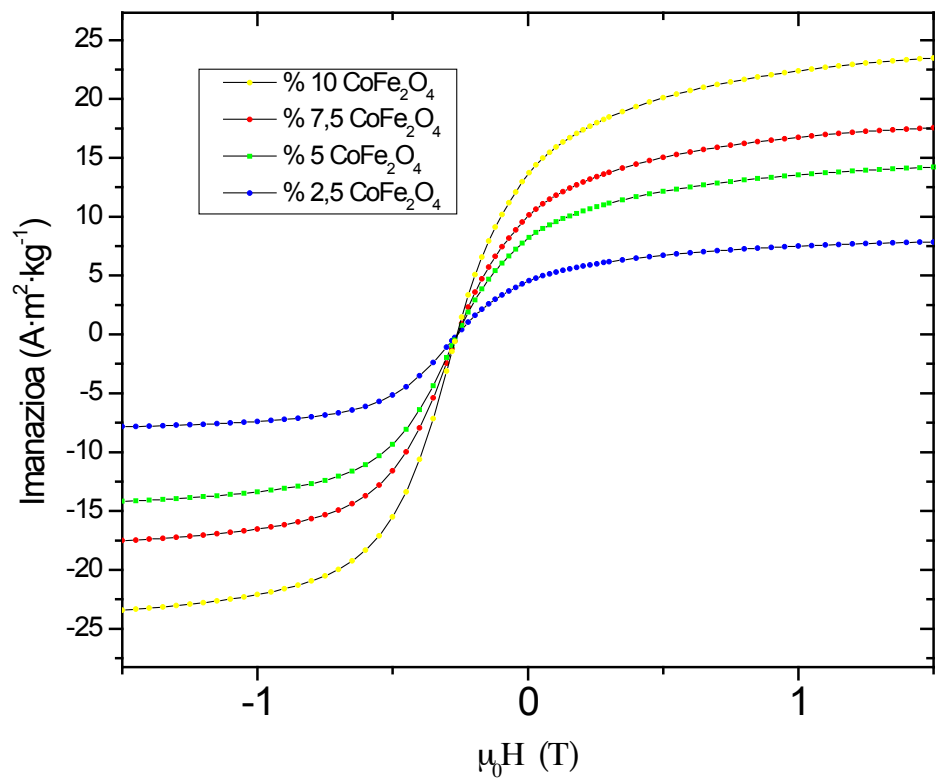

14. irudia. $\mathrm{CoFe}_{2} \mathrm{O}_{4}$ nanopartikuladun PUzko histeresi-kurbak.

\section{ONDORIOAK}

Konpositeen poliuretanoa sortzeko eta aukeratzeko, pisu molekular ezberdinetako (kate luzera desberdinetako) hiru masa molar ezberdineko PTMG erabili dira: 250,650 eta $1000 \mathrm{~g} \cdot \mathrm{mol}^{-1}$, eta PU onena, $250 \mathrm{~g} \cdot \mathrm{mol}^{-1}$ pisu molekularrekoa izan da, zati biguna txikiagoa delako. PTMG gero eta luzeagoa izanik, zati biguna handiagoa izango da eta zurruntasuna galduko $\mathrm{du}$, eta elastikotasuna irabazi. Izan ere, lan honetan oso lodiera txikiko azalerak sortu dira $(0,1 ; 0,2$ eta $0,4 \mathrm{~mm}$-koak), eta film hauen zurruntasuna oso handia ez bada, oso erraz apurtzen dira. Beraz, $250 \mathrm{~g} \cdot \mathrm{mol}^{-1}$ pisu mo- 
lekularreko PTMGk zati biguna txikiagoa izatea baimentzen du, zurruntasuna igoz, eta, film lodiera txikia denez, elastikotasun altua mantentzen du, zurruntasun nahiko ona izanez eta gainerako filmekiko haustura erresistentzia altuagoa izanik.

Konpositeen sintesian, partikulak azken momentuan gehitzeak asko hobetzen du konpositeen egitura asko, zeren partikulen homogeneotasuna altuago eta matrize polimeriko gogorrago eta elastikoagoa lortzen baita. Gainera, partikulen gehitzea zenbat eta handiagoa izan, matrize polimerikoaren izaera txikiagoa izango da, eta konpositeen zurruntasuna igotzen da. Partikula hauekin hain zuzen, ikusi da bolumenean $\% 10$ partikula izanik konpositea ez dela malgua hauskorra baizik.

Kalorimetria frogetan ondoriozta dezakegu partikulek eragina izan dutela beira-trantsizioan, partikula bakoitzak urtze-tenperatura ezberdina duelako eta partikula-polimero arteko interfasea (hau da, polimero eta partikulen arteko elkarrekintza) ezberdina delako. Oro har, partikulek beira trantsizio tenperatura jaisten dute, hau da, partikulei esker poliuretanoen malgutasuna errazago mantentzen da tenperatura baxuagoetan. Partikulak oztopoak sortzen dituzte alde amorfoko guneetan, eta beira-egitura bezala paketatzeko erraztasuna jaitsi egiten da [14].

Azkenik, VSMaren karakterizazioan, konpositeek zenbat eta partikula kantitate handiago izan, saturaziozko imanazio handiagoa dute, hots, magnetikoagoak dira eta eremu indartsuagoak sortzen dituzte. Bestalde, hondarretako balioak ikusita, partikula ferromagnetiko sendoen kasuan gaude, konposite bakoitzaren $\mathrm{M}_{\mathrm{R}}>0,5 \cdot \mathrm{M}_{\mathrm{S}}$ direlako. Hori emaitza ona da, nahi dugun aplikazioak sentikortasun magnetiko altua eskatzen duelako, hau da, eremu magnetiko minimo batekin azalera aldaketa bat bermatzen duen konpositea lortzen da [15].

\section{ESKER ONAK}

Egileek sostengu ekonomikoa eskertzen diete Eusko Jaurlaritzaren Ekonomiaren Garapena eta Azpiegituren Sailari, ELKARTEK-i (MMMfavIN), bai eta Dr. Daniel Salazarri ere partikula magnetikoen neurketak egiteagatik. Halaber, egileek esker onez onartzen dute Euskal Autonomia Erkidegoko Gobernuaren finantziazioa (IT718-13 ikerketa-taldea).

\section{BIBLIOGRAFIA}

[1] Posada, A. O.; Tellez, D. A. L.; Rojas, J.; Barrado, J. 2017 «Materiales compuestos de matriz polimérica usados para el blindaje de interferencia electromagnética». Cienc. e Ing. Neogranadina 27, 5-26. 
[2] Fulco, A. P.; Melo, J. D.; Paskocimas, C. A. 2016. «Magnetic properties of polymer matrix composites with embedded ferrite particles». NDT E Int, 77, 42-48.

[3] Aguilar Ayala, R. D. 2019. «Caracterización mecánica de materiales compuestos de matriz polimérica PEBD reforzados con partículas de hierro»Universidad Autónoma Del Estado de México, 9-29.

[4] Furtwengler, P. eta Avérous, L. 2018. «Renewable Polyols for advanced polyurethane foams from diverse biomass resources». Polym. Chem. 9, 4258-4287.

[5] Gite, V.V.; Mahulikar, P.P.; Hundiwale, D.G. 2010. «Preparation and properties of polyurethane coatings based on acrylic polyols and trimer of isophorone diisocyanate». Progress in Organic Coatings 68, 307-312.

[6] Chattopadhyay, D. K.; Kothepalli, R. 2007. «Structural Engineering of Polyurethane Coatings for High Performance Applications». Progress in Polymer Science 32, 352-418.

[7] Gupta, A.; Maharjan, A.; Soo Kim, B. 2019. «Shape Memory Polyurethane and its Composites for Various Applications». Applied Sciences 21.

[8] Hermida. 2011 «Polímeros. Capitulo 9» Ministerio de Educacion, Buenos Aires: Argentina. 1-99.

[9] Alvarez, C. R. 2008. «Elastómeros magnetostrictivos de poliuretano y terfenol-D: síntesis y propiedades». Tesia. Euskal Herriko Unibertsitatea, Leioa. 49-73.

[10] De Oca, J. M.; Chuquisengo, L.; Alarcón, H. 2010. «Síntesis y caracterización de nanopartículas de ferrita de cobalto obtenidas por el proceso solgel». Soc. Química del Perú, 76, 400-406.

[11] Serrano, X. P. 2019. «Comportamiento reologico de suspensiones de fibra de celulosa modificadas con nanoparticulas magneticas de ferrita de cobalto». Universidad Pontificada Bolibariana, 20-23.

[12] Taguado, M.; Vilas, J. L.; Veloso, A. 2020. «Síntesis y caracterización de poliuretanos biocompatibles con memoria de forma». Euskal Herriko Unibertsitatea, Leioa, 5-11.

[13] RegueIRA, J. R. M. 2009. «Síntesis y caracterización de sistemas nanoparticulados en base de hierro». Euskal Herriko Unibertsitatea, Leioa, 28-121.

[14] Tognana, S.; Salgueiro, W. 2007. «Sobre la interfase particula-matriz en compuetos particulados de matriz epoxi». Facultad de ciencia exacta, Argentina, 19, 218-221.

[15] Salazar, D.; Aubert, A.; Garitaonaindia, J. S. 2020. «Structural and magnetic propertie of Nd-Fe-Mo-(N) melt-spun ribbons with $\mathrm{ThMn}_{12}$ structure». Basque Center for Material, Application and Nanostructures (BCMaterials), Leioa, 519-526. 